\title{
Interaction of an Endotoxin with Cationic Macromolecules
}

\author{
By P. T. MORA AND B. G. YOUNG \\ National Cancer Institute, National Institutes of Health, Bethesda, Maryland, U.S.A.
}

(Received 8 February 1961)

SUMMARY

The interaction of the anionic lipopolysaccharide complex isolated from a Gramnegative bacterium (Serratia marcescens) was studied in aqueous and saline solution with several cationic macromolecules, with the object of selectively inhibiting certain of the biological activities of this polysaccharide endotoxin. Incubation with lysozyme decreased the pyrogenic activity, while the tumour-damaging ability of this polysaccharide remained high. This was in contrast to interaction with RNase and with polymyxin $\mathrm{B}$, in which cases the tumour-damaging activity was decreased while the pyrogenic activity was not affected. Ultracentrifuge experiments indicated that both the tumour-necrotic and especially the fever-producing fractions of this bacterial polysaccharide preparation are of much higher molecular weight $(>10 S)$ than the major component $(3 \cdot 4 S)$, which is either inactive or of low activity. The highest molecular weight fever-producing components appeared to be broken down in an enzymic type of process by the lysozyme.

\section{INTRODUCTION}

The endotoxins from Gram-negative bacteria are high molecular weight lipopolysaccharide complexes which exhibit a whole array of biologic properties when injected into animals in microgram quantities: they are toxic and antigenic, produce fever, cause localized haemorrhage and necrosis in prepared skin sites and in tumours, etc. (cf. Burrows, 1951; Thomas, 1954). There is no a priori reason why all of these different biological properties should be caused by the same morphological or physico-chemical entity. For example, it might be that those components or molecular sites in the complex which cause the tumour-damaging activity are not the ones which cause the fever. However, prior attempts to separate the physicochemical entities responsible for these different biological activities have all resulted in failure and no fractionation or other method has been found to be effective (Rathgeb \& Sylven, 1954; Malmgren, 1954; Creech, Koehler, Havas, Peck \& Andre, 1954). The general opinion developed that the biological activities are just different manifestations of host reactions to the same physico-chemical entity. When hydrolysis or some other means of splitting the endotoxic lipopolysaccharide complex was tried it led to a total loss of the activities (Rathgeb \& Sylven, 1954; Ikawa, Koepfli, Mudd \& Niemann, 1952, 1954; Merler, Perrault, Saroff \& Mora, to be published). Only when a certain macromolecular size and complexity was maintained, after gentler treatment, were the biological activities retained (Fromme, Luderitz, Nowotny \& Westphal 1958; Westphal et al. 1958; Ribi et al. 1960).

It occurred to us that selective or preferential macromolecular interaction with different components, or sites, of the bacterial polysaccharide preparations might 
separate some of these biological properties, while maintaining the necessary macromolecular size.

We reported previously on the blocking of enzyme activity and of toxicity through interaction of oppositely charged macromolecules (Mora \& Young, 1958; Mora, Young \& Shear, 1959). This approach has been extended to the study of the interaction of a bacterial lipopolysaccharide preparation from Serratia marcescens of negative net charge near neutral $\mathrm{pH}$, with positive (cationic) macromolecules. The cationic macromolecules used were polymyxin B, ribonuclease, lysozyme and protamine. Changes in pyrogenic potency and tumour damaging activity were then examined. There was previous evidence that cationic macromolecules affect some of the biological properties of endotoxin preparations (Fisher, 1959; Neter et al. 1958). We also studied the possibility of reversal of some of these changes of pyrogenic and tumour damaging activities, when a strong anionic synthetic polysaccharide preparation (polyglucose sulphate) was also added. This was expected to break up the interaction of the macromolecules by preferentially forming a complex with the cationic macromolecules and to restore the biological activity of the anionic bacterial polysaccharide. We found that interaction with lysozyme was qualitatively different from interaction with the other cationic macromolecules; there also was indication of a simultaneous enzymic action.

\section{METHODS}

\section{Materials}

The endotoxic polysaccharide complex from Serratia marcescens (referred to from now on as 'bacterial polysaccharide') was preparation P-25 of A. Perrault, obtained by a modification of the method of Shear \& Turner (1943). Fractionation and chemical experiments (Rathgeb \& Sylven, 1954a, b), electrophoretic and ultracentrifuge studies (Malmgren, 1954) have been carried out previously on this preparation, as well as extensive biological studies.

The cationic macromolecules used were: polymyxin B (Pfizer no. $5 \times 070$ ), crystalline ribonuclease (Armour no. 381-059), protamine sulphate (Nutritional Biochemicals Corp. no. 9193), and lysozyme. Lysozyme was used either as obtained commercially (Nutritional Biochemicals Corp. nos. 1417 and 7545) which gave a neutral solution or, when so specified, in a form which we will designate 'basic lysozyme'. This 'basic lysozyme' was obtained from the commercial preparation by bringing to $\mathrm{pH} 11 \cdot 4$ with dilute $\mathrm{NaOH}$ in an aqueous solution and then dialysing this solution in heat-treated cellophan and freeze-drying the residue; this 'basic lysozyme' upon re-solution in water gave a $\mathrm{pH}$ of $\mathbf{9}$.

The anionic polysaccharide derivative was a sulphated polyglucose prepared from a chemically synthesized polyglucose (number average mol. wt. about 20,000) by treatment by chlorosulphonic acid (Prep. H; Wood \& Mora, 1958). The polyglucose sulphate contained three sulphate groups per anhydroglucose unit and had intrinsic viscosity $(\eta)=0.04$. The sodium salt or the acid form was used.

\section{Interaction}

Interaction of the cationic macromolecules with the bacterial polysaccharide was achieved by mixing dilute aqueous solutions followed by incubation for different 
lengths of time. A representative example was as follows: $100 \mu \mathrm{g}$. bacterial polysaccharide plus the appropriate amount of basic protein was incubated in $5 \mathrm{ml}$. pyrogen-free water at $37^{\circ}$ for $16 \mathrm{hr}$. The solution was then diluted with pyrogen-free water for assay of tumour-damaging potency. In the reversal experiments, a concentrated aqueous solution of polyglucose sulphate was added to the incubated aqueous mixture of bacterial polysaccharide and basic protein, further incubated for $1 \mathrm{hr}$. at $37^{\circ}$, diluted with water and assayed. In the pyrogenic test the final diluent was $0.9 \% \mathrm{NaCl}$ solution.

\section{Bioassays}

Tumour-damaging potency was measured in mice bearing 6-day intramuscular implants of Sarcoma 37, using a method which, with minor variations (Shear, Perrault \& Adams, 1943; Landy \& Shear, 1957) has been routinely employed in this Laboratory for many years. A few micrograms of the bacterial polysaccharide usually produced, within $24 \mathrm{hr}$. after intraperitoneal injection, haemorrhage and necrosis in the tumours. In the untreated controls the tumours showed no haemorrhage. Affected tumours were those which showed extensive, freshly induced haemorrhage. A minimum of ten mice was used for each dose level. The minimum effective dose (ED50; the dose which produced extensive damage in tumours of half of the mice) was $5 \mu \mathrm{g}$.; this value was reproducible within about $\pm 50 \%$.

Pyrogenic activity was measured in rabbits by observing the elevation in rectal temperature under conditions previously described (Landy \& Shear, 1957). Lysozyme (16 mg.) was mixed with $20 \mu \mathrm{g}$. bacterial polysaccharide, and in the reversal experiment, in addition, with $24 \mathrm{mg}$. polyglucose sodium sulphate in $1 \mathrm{ml}$. solution of pyrogen-free water. These aqueous mixtures were incubated for different periods of time at $37^{\circ}$. Thirty minutes before the injection, these concentrated mixtures were diluted with pyrogen-free $0.9 \% \mathrm{NaCl}$ solution, and $1 \mathrm{ml}$. samples were injected into the ear vein of the rabbit. The temperature change was then recorded. Four rabbits were used for each dose level. The minimum pyrogenic dose (MPD) of the bacterial polysaccharide was $0.006 \mu \mathrm{g}$. $( \pm 50 \%)$; this produced at least $1^{\circ} \mathrm{F}$. fever.

The enzymic potency of lysozyme was determined by measuring the decrease of optical density during the lysis of a suspension of the ultraviolet-treated Micrococcus lysodeicticus (Skarnes \& Watson, 1955). The lysis was complete in $30 \mathrm{~min}$. The assay provided a method with an error of about $5 \%$.

\section{Chemical methods}

The concentration of bacterial polysaccharide was determined by the anthrone procedure, comparing the absorbency at $620 \mathrm{~m} \mu$ with that of solutions of known concentration.

Lysozyme or ribonuclease concentrations, in interaction complexes with the bacterial polysaccharide, were estimated after adding salt to bring the mixtures to $0.9 \% \mathrm{NaCl}$ concentration (which was sufficient to dissolve the precipitates) and then measuring the absorbency of the clear solutions at $280 \mathrm{~m} \mu$ and calculating the protein concentration from calibration data. The absorbency due to the bacterial polysaccharide was below the average experimental error (about 5\%), and was not used as a correction factor. 
Dialysis experiments were carried out in du Pont 400 'gel' cellophan against running distilled water for $64 \mathrm{hr}$.

\section{Ultracentrifuge experiments}

All analytical centrifugation was performed with the Model E Spinco ultracentrifuge using schlieren optics. In the ultracentrifuge experiments the bacterial polysaccharide concentration was $1 \%$ in $0 \cdot 154 \mathrm{M}$-sodium chloride at $25^{\circ}$. Sedimentation constants are expressed in Svedberg units $S=S_{20 w}^{\circ} \times 10^{-13} \mathrm{~cm} . / \mathrm{sec}$. after correction to water at $20^{\circ}$ and using the value of 0.6095 for partial specific volume of the bacterial polysaccharide. The moving platform cell and method of Yphantis \& Waugh $(1956 a, b)$ was used in the partition cell analysis experiments.

In the partition cell analysis the centrifugation was at top speed $(59,780 \mathrm{rev} . / \mathrm{min}$.), and the acceleration and deceleration of the rotor was carefully recorded. After centrifugation the supernatant (upper half), subnatant (lower half of the solution which remained below the partition), rinse of the lower half of the cell, and also an uncentrifuged control solution, were all bioassayed for tumour-damaging activity. Serial dilutions were carried out until the tumour-damaging activity showed a linear decrease with dilution, and the ED50 was determined. The amount of the original tumour-damaging activity present in the particular portion of the cell (upper half, lower half, lower rinse) was then estimated from such data. The pyrogenic activity of these solutions was then similarly determined. In the uncentrifuged control solution the tumour-damaging activity and the pyrogenic activity was present in the expected ratio (ED 50 (tumour) $5 \mu \mathrm{g} . /$ mouse, MPD (fever) 0.006 $\mu \mathrm{g}$./ rabbit). From bioassays of the supernatant the sedimentation constant was calculated for both the tumour-damaging and for the fever-producing material. The partition cell analysis essentially followed the method suggested by Yphantis \& Waugh $(1956 b)$ and the calculations took into account the integrated angular velocity during acceleration and deceleration as well as during top speed centrifugation (cf. equations 1-4, Yphantis \& Waugh, 1956a). The calculated value for the sedimentation constant of the biologically active material was found to vary $\pm 0.5 S$ if $\pm 100 \%$ error was assumed in the bioassays.

\section{RESULTS}

\section{Biological and chemical evidence for interaction}

The bacterial polysaccharide at 10-15 $\mu \mathrm{g}$./mouse caused severe damage in the tumours of most of the mice (Table 1 ). The same amount of bacterial polysaccharide affected only a small percentage of the tumours after incubation for 30 min. with ribonuclease, polymyxin B, or protamine. Similar incubation with lysozyme, however, led to an opposite result: the tumour-damaging effect of the bacterial polysaccharide increased. The data presented in Table 1 are representative of many such experiments, and also illustrate the reproducibility of the tumour assay.

When polyglucose sulphate was added to the solution containing the bacterial polysaccharide and the polymyxin or RNase, and the incubation was continued for another $\frac{1}{2} \mathrm{hr}$., the decrease in tumour-damaging activity was reversed, and the bacterial polysaccharide essentially recovered its original tumour-damaging activity. 
In the case of the solution with lysozyme, the increase in tumour-damaging activity was reversed after further incubation with polyglucose sulphate, and the activity decreased below that of the control.

Table 1. Tumour-damaging effect of Serratia marcescens polysaccharide and the effect of incubation with cationic macromolecules and polyglucose sulphate

\begin{tabular}{|c|c|c|c|c|c|c|c|c|}
\hline & & & & After in & ubati & ith & & \\
\hline & $\begin{array}{l}\text { Bacterial } \\
\text { ysacchari } \\
\text { re incubat }\end{array}$ & & Cationic ma & omolecule & & $\begin{array}{r}\text { Catior } \\
\text { a } \\
\text { poly }\end{array}$ & $\begin{array}{l}\text { ic macrom } \\
\text { ad then w } \\
\text { glucose sul }\end{array}$ & ecule \\
\hline & $\begin{array}{l}\text { Damaged } \\
\text { tumours }\end{array}$ & & & $\begin{array}{l}\text { Damaged } \\
\text { tumours }\end{array}$ & & & $\begin{array}{l}\text { Damaged } \\
\text { tumours }\end{array}$ & \\
\hline ng. & no. & $\%$ & mg. & no. & $\%$ & mg. & no. & $\%$ \\
\hline 015 & $17 / 20$ & 85 & 1 ribonuclease & $2 / 19$ & 10 & $0 \cdot 75$ & $11 / 20$ & 55 \\
\hline 015 & $17 / 20$ & 85 & 1 ribonuclease & $4 / 19$ & 21 & $0 \cdot 5$ & $19 / 20$ & 95 \\
\hline 015 & $37 / 40$ & 92 & 1 ribonuclease & $12 / 39$ & 31 & $0 \cdot 5$ & $20 / 20$ & 100 \\
\hline 015 & $17 / 20$ & 85 & 0.5 ribonuclease & $6 / 20$ & 30 & $0 \cdot 5$ & $19 / 20$ & 95 \\
\hline 010 & $17 / 20$ & 85 & 0.25 ribonuclease & $2 / 15$ & 13 & 0.5 & $15 / 15$ & 100 \\
\hline$\cdot 015$ & $17 / 19$ & 89 & $0 \cdot 4$ polymyxin-B & $1 / 16$ & 6 & 0.5 & $15 / 20$ & 75 \\
\hline 005 & $7 / 15$ & 47 & 2 lysozyme & $15 / 15$ & 100 & 1 & $2 / 10$ & 20 \\
\hline
\end{tabular}

Lysozyme abolished the pyrogenicity of ten times the amount of the minimum pyrogenic dose of the bacterial polysaccharide, while no such effect appeared after incubation with the other cationic macromolecules. However, the concentration of the bacterial polysaccharide had to be sufficiently high $(20 \mu \mathrm{g} . / \mathrm{ml}$.) and the incubation had to proceed for a sufficient length of time (1-2 weeks) to obtain consistent and large decrease in pyrogenicity. Bacterial polysaccharide (20 $\mu \mathrm{g}$.) and commercial lysozyme (16 mg.) were incubated together in $1 \mathrm{ml}$. of water at $37^{\circ}$ for different lengths of time; Fig. 1 gives the average fever curves obtained with various dilutions of this mixture. The control curves were obtained with solutions of the bacterial polysaccharide incubated at $37^{\circ}$ without lysozyme.

The presence of sodium polyglycose sulphate abolished lysozyme's ability to reduce the fever-producing activity of the bacterial polysaccharide. When lysozyme (16 $\mathrm{mg}$.) and sodium polyglucose sulphate $(24 \mathrm{mg}$.) were admixed in this ratio (which was known to inhibit completely the enzyme activity; Mora \& Young, 1959), and this mixture was then incubated with the bacterial polysaccharide (20 $\mu \mathrm{g}$.) in $1 \mathrm{ml}$. water, the fever-producing activity of the bacterial polysaccharide was retained even after incubation for 1 or 2 weeks at $37^{\circ}$ (Fig. 2). Apparently the polyglucose sulphate complexed with the lysozyme, as indicated by the appearance of white turbidity, and the action of the lysozyme on the bacterial polysaccharide was inhibited.

Lysozyme decreased the tumour-damaging effect of the bacterial polysaccharide, but to a smaller extent: to about one-half of the original bacterial polysaccharide activity after 2 weeks' incubation at $37^{\circ}$. The bacterial polysaccharide itself did not lose activity after similar incubation.

Thus, the effect of lysozyme on the bacterial polysaccharide was different from the other cationic macromolecules, and indicated that two processes might be 
involved: first, an immediate effect, probably due to macromolecular interaction, and secondly, a slower, probably enzymic reaction. The following experiments were carried out to clarify the nature of the lysozyme-bacterial polysaccharide interaction.

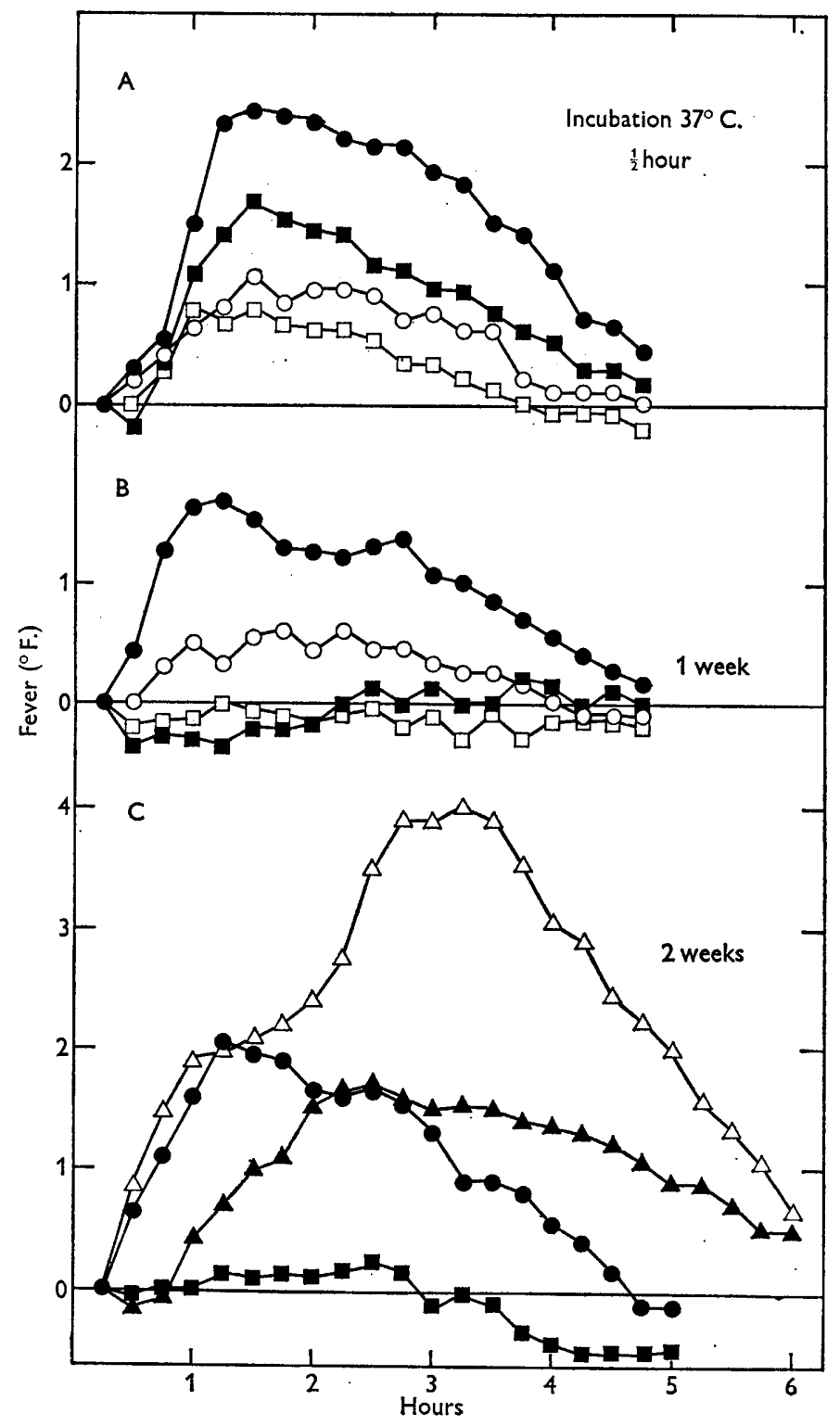

Fig. 1. Pyrogenicity in rabbits of the bacterial polysaccharide after different periods of incubation $\left(37^{\circ}\right)$ with lysozyme. Each point represents average fever from four rabbits after injection. A. Incubation $\frac{1}{2} \mathrm{hr}$., $O=0.01 \mu \mathrm{g}$. polysaccharide/rabbit, $\square=0.01 \mu \mathrm{g}$. polysaccharide $+8 \mu \mathrm{g}$. lysozyme, $Q=0.1 \mu \mathrm{g}$. polysaccharide, $\square=0.1 \mu \mathrm{g}$. poly. saccharide $+80 \mu \mathrm{g}$. lysozyme. B. The same after incubation for 1 week. C. After 2 weeks incubation, $\Delta=1 \mu \mathrm{g}$. polysaccharide, $\Delta=1 \mu \mathrm{g}$. polysaccharide $+800 \mu \mathrm{g}$. lysozyme; and $\boldsymbol{a s}$ in $\mathrm{A}$. 
The bacterial polysaccharide $\left(10 \mathrm{mg}\right.$.) was titrated at $0^{\circ}$ in aqueous solution with 'basic lysozyme'. Figure 3 shows the changes in pH and in optical density. Neutralization occurred after 1.5-2 times as much lysozyme as polysaccharide was added, and also in this same range the optical density (turbidity) increased at a rapid rate. After $28 \mathrm{mg}$. lysozyme had been added (see arrow in Fig. 3) an aliquot of the suspension was set aside for further studies (see below). The titration was

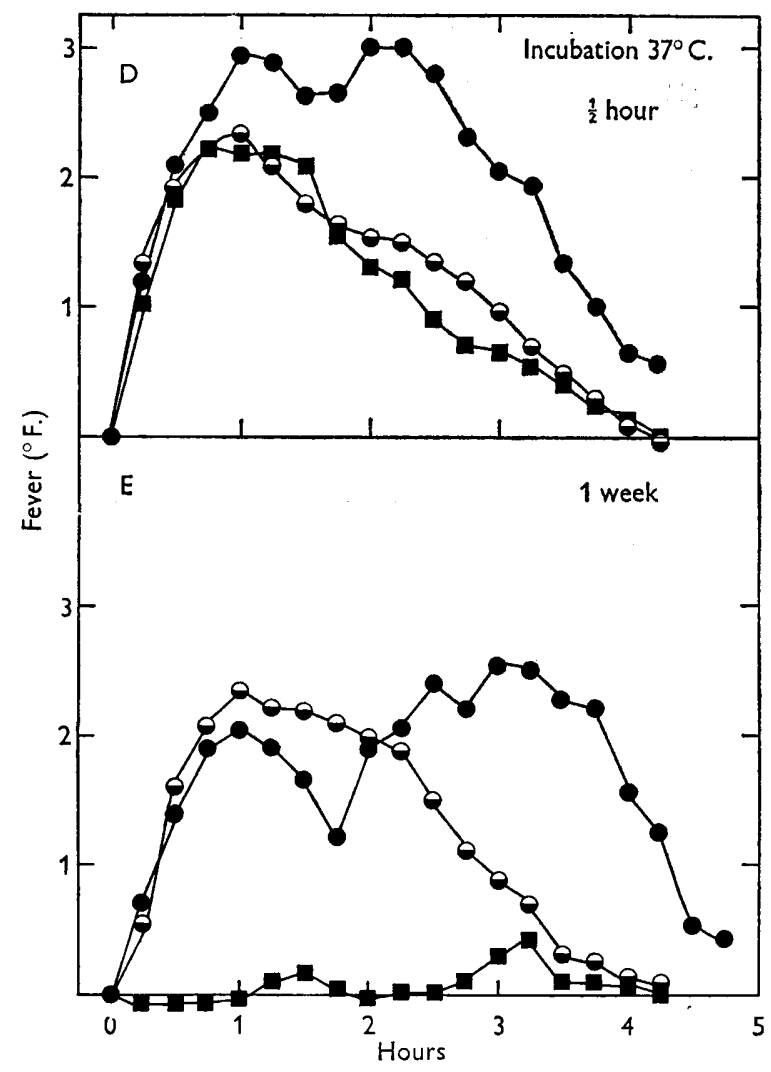

Fig. 2. Inhibition by polyglucose sulphate of lysozyme's ability to decrease pyrogenicity. D. Incubation $\frac{1}{2} \mathrm{hr} ., 37^{\circ}, \quad=0.1 \mu \mathrm{g}$. bacterial polysaccharide, $\square=0.1 \mu \mathrm{g}$. polysaccharide $+80 \mu \mathrm{g}$. lysozyme, $\ominus=90 \mu \mathrm{g}$. lysozyme $+120 \mu \mathrm{g}$. polyglucose sulphate sodium salt $+0 \cdot 1 \mu \mathrm{g}$. polysaccharide. E. The same after 1 week incubation. Notice that the effect of lysozyme (E) was inhibited by polyglucose sulphate $(\ominus)$. Results were similar after 2 weeks incubation.

continued on the remainder but there was no indication of further neutralization or precipitate formation (dashed line, Fig. 3). When sodium chloride was added to the final turbid suspension containing the excess lysozyme (establishing $0 \cdot 1 \mathrm{~N}-\mathrm{NaCl}$ conc.) the precipitate rapidly dissolved $(D=0 \cdot 154)$ indicating dissociation of the complex. Similar immediate clearing occurred after adding a few drops of $\mathrm{N}-\mathrm{NaOH}$ $(D=0.076, \mathrm{pH}=12 \cdot 7)$.

One part of the aqueous suspension titrated to the point indicated by the arrow in Fig. 3 was centrifuged to collect the insoluble precipitate. To another part of the 


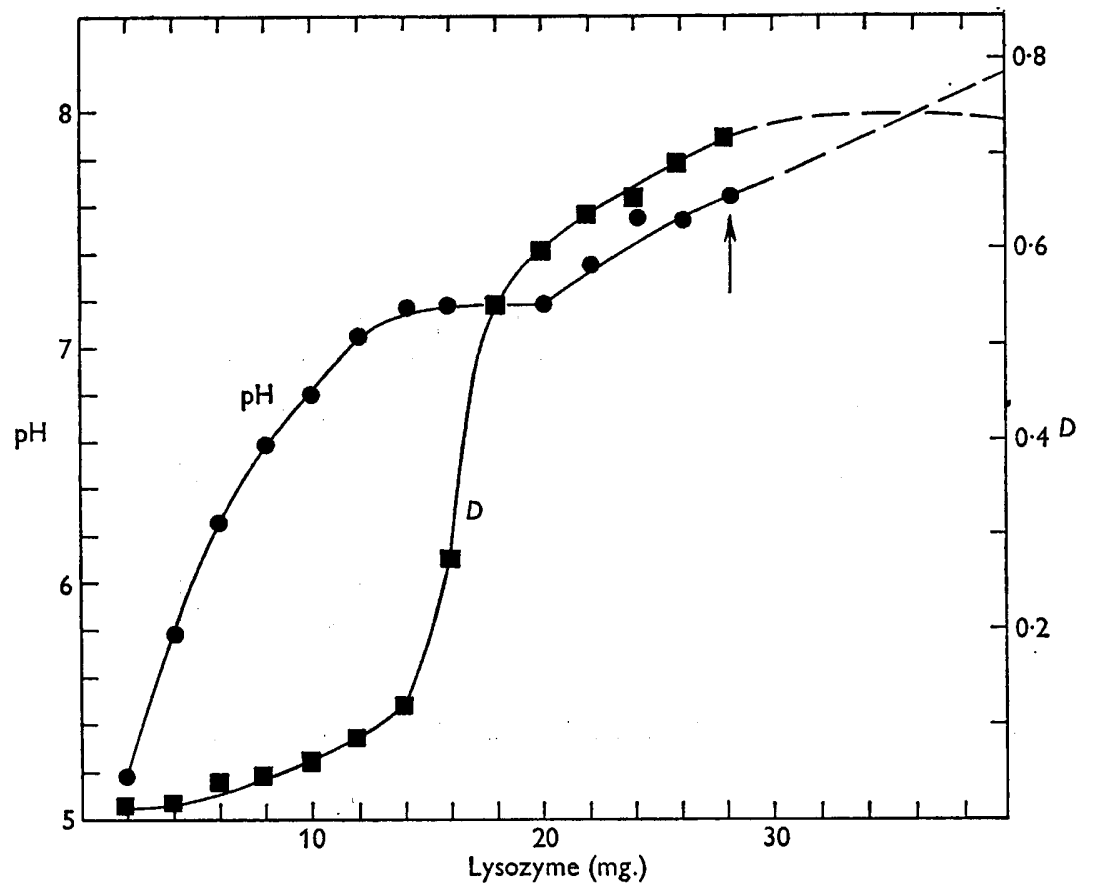

Fig. 3. Titration of bacterial polysaccharide ( $10 \mathrm{mg}$.) with 'basic lysozyme' in aqueous solution at $0^{\circ}$; changes in $\mathrm{pH}$, and in optical density $(D)$ at $640 \mathrm{~m} \mu$.

suspension solid sodium chloride was added to establish $0 \cdot 154 \mathrm{M}$-concentration before centrifugation, thereby bringing about a dissociation by the salt similar to that which would be expected upon injection into body fluids. The supernatant fluids and the sediments from both the aqueous and from the saline solution were then analysed chemically for bacterial polysaccharide and for lysozyme concentration, and also

Table 2. Interaction of bacterial polysaccharide with basic lysozyme in aqueous and in saline solutions; separation of material and of biologic activity into soluble and sedimenting fractions

$$
\begin{aligned}
& 10 \mathrm{mg} \text {. bacterial polysaccharide titrated with } \\
& 28 \mathrm{mg} \text {. basic lysozyme in aqueous solution }
\end{aligned}
$$

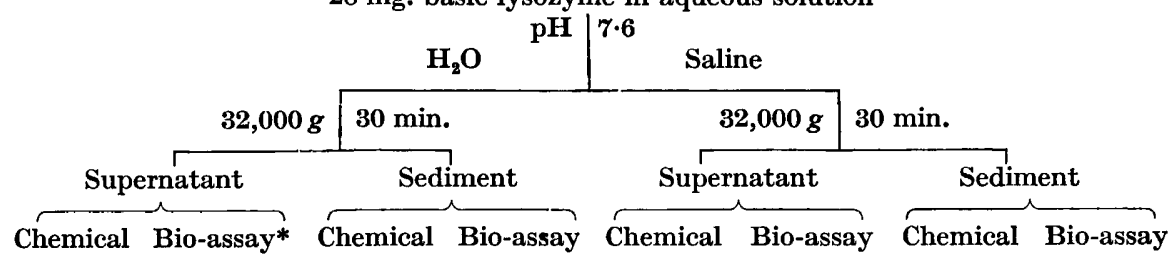

Chemical Bio-assay* Chemical Bio-assay Chemical Bio-assay Chemical Bio-assay

Bacterial polysacch.

Lysozyme

$\begin{array}{llllllll}31 & 50 & 58 & 50 & 78 & 100 & 22 & 0 \\ 51 & 24 & 57 & 24 & 84 & 60 & 16 & 0\end{array}$

* Bioassay of bacterial polysaccharide by tumour-necrotic potency. Determinations were carried out in serial dilutions and on sufficient tumour-bearing animals to make the estimate valid $\pm 10 \%$.

Bioassay of lysozyme by enzymic potency, see p. 83 . 
tested biologically for tumour-damaging potency and for lysozyme activity on M. lysodeicticus (Table 2).

The sediment obtained from the preparation in water contained about half of the bacterial polysaccharide with unimpaired tumour-damaging potency. Half of the lysozyme was also in this sediment, but the enzymic activity decreased to about one-quarter of the total. In the supernantant fluid the bacterial polysaccharide had high potency, while lysozyme activity was only one-half of what would have been expected on the basis of the chemical concentration, indicating that a soluble complex was present, but without decrease of the tumour-damaging activity of the bacterial polysaccharide in such a complex.

In saline solution, $22 \%$ of the bacterial polysaccharide was present in the sediment without having demonstrable tumour-damaging activity, but still all the starting tumour necrotic potency was accounted for in the remaining $78 \%$ concentration in the supernatant fluid. Lysozyme enzymic activity was somewhat decreased in the supernatant fluid, while there was no activity in the precipitate.

Dialysis experiments were carried out on aqueous and saline solutions of the bacterial polysaccharide interaction product with excess lysozyme, under conditions in which all the free lysozyme was demonstrated to be eliminated in a control experiment. Table 3 gives the final ratios in the supernatant fluids after dialysis against water and saline solution. Similar data are included on the dialysis of the interaction products of the bacterial polysaccharide and ribonuclease. In both aqueous and saline media the ratio of interacted (non-dialysable) bacterial polysaccharide to lysozyme or to ribonuclease was about one to two.

Table 3. Dialysis of interaction products of the bacterial polysaccharide with basic lysozyme and with RNase in water and in saline solution

\begin{tabular}{|c|c|c|c|c|}
\hline & \multicolumn{2}{|c|}{$\begin{array}{l}\text { Interaction in water } \\
\text { Ratio in dialysate* of } b\end{array}$} & \multicolumn{2}{|c|}{$\begin{array}{l}\text { Interaction in } 0.9 \% \mathrm{~N}_{2} \mathrm{Cl} \\
\text { erial polysaccharide to: }\end{array}$} \\
\hline & Lysozyme & Ribonuclease & Lysozyme & Ribonuclease \\
\hline \multirow{2}{*}{ Dialysed: against water } & 1 & 1 & 1 & 1 \\
\hline & $\overline{\mathbf{1} \cdot 9}$ & $\overline{1 \cdot 8}$ & $\overline{1 \cdot 4}$ & $\overline{1 \cdot 9}$ \\
\hline \multirow{2}{*}{ against saline } & 1 & 1 & 1 & 1 \\
\hline & $\overline{1.9}$ & $\overline{2 \cdot 6}$ & $\overline{1.9}$ & $\overline{\mathbf{2 \cdot 2}}$ \\
\hline & The portion & aining after di & & \\
\hline
\end{tabular}

Ultracentrifuge sedimentation of the bacterial polysaccharide shows a major component with $3 \cdot 4 S$ and several faster sedimenting components $(6 \cdot 9,10 \cdot 5$ and $11 \cdot 5 S$ ) of much higher molecular weights, with the second summit being at $10 \cdot 5 S$ (Fig. 4. A).

Three partition cell analyses were carried out. In the first experiment the bacterial polysaccharide was centrifuged until all the higher molecular weight components passed into the lower half of the cell, but some of the slowest sedimenting material was retained in the upper half (Fig. 4B). In the second experiment the solution was centrifuged for a shorter time, which resulted in retaining also some of the faster sedimenting components in the upper half of the cell (Fig. 4C). 
In the third experiment an interaction product of bacterial polysaccharide and lysozyme was centrifuged.

When the bacterial polysaccharide (10 mg.) interacted in aqueous solution ( $1 \mathrm{ml}$.) with basic lysozyme ( $28 \mathrm{mg}$.), as in the titration experiment above, a precipitate formed, which largely dissolved when the sodium chloride concentration was brought to $0 \cdot 154 \mathrm{M}$. The small amount of residual insoluble material was separated by low speed centrifugation $(2150 \mathrm{~g})$ and the supernatant was kept for $16 \mathrm{hr}$. at $4^{\circ}$. After this the supernatant fluid had only two slow-moving components in the analytical cell, with $1.92 S$ and $3.86 S$, and no faster sedimenting components (Fig. 4D).

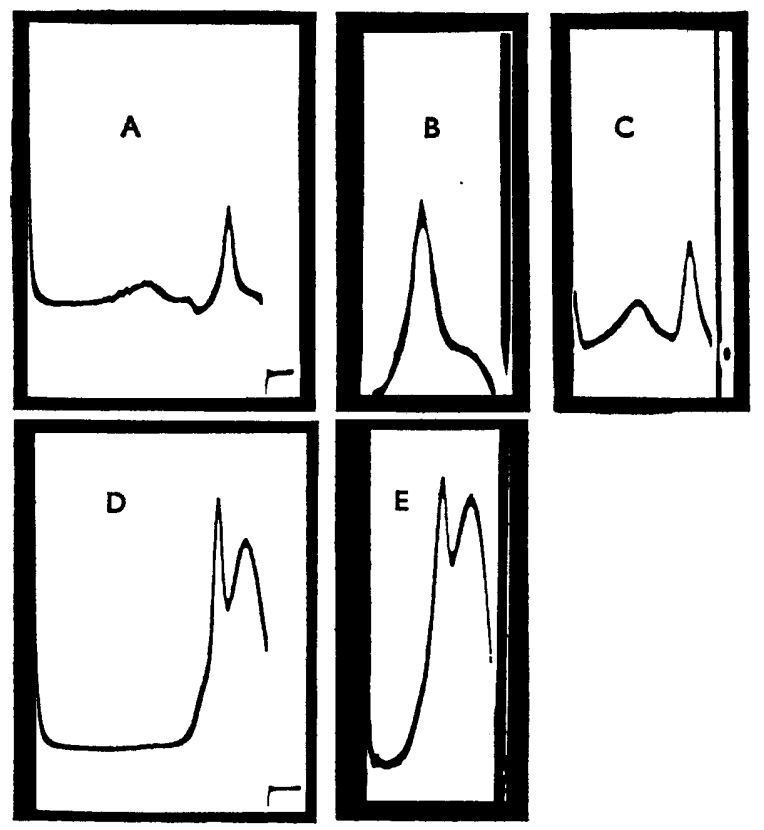

Fig. 4. Sedimentation of bacterial polysaccharide and of the complex with lysozyme in the ultracentrifuge. In all experiments bacterial polysaccharide conc. was $1 \%$ in $0 \cdot 154 \mathrm{M}-\mathrm{NaCl}$; temp. $25^{\circ}$; centrifugation at top speed (59,780 rev. min.). Sedimentation from right to left. A. Bacterial polysaccharide in analytical cell after $30 \mathrm{~min}$. B. Same in the moving partition cell. Photograph taken during deceleration at $2000 \mathrm{rev}$. min. after the moving partition re-occupied its median position; the lower half of the cell is dark because the light is blocked out by the supports of the partition. Total effective sedimentation time corrected to top speeds $66 \mathrm{~min}$. C. The same. Total effective sedimentations time 20.70 min. D. Bacterial polysaccharide and lysozyme (orig. conc. $2 \cdot 8 \%$ ) after $30 \mathrm{~min}$. at top speed. E. The same in the moving partition cell during deceleration at $2000 \mathrm{rev}$. min. Total effective sedimentation time $41 \cdot 27 \mathrm{~min}$.

In the third partition cell experiment the supernatant from the low-speed centrifugation of the bacterial polysaccharide + basic lysozyme mixture was sedimented to the extent shown in Fig. $4 \mathrm{E}$.

In each partition experiment solutions from the upper and lower half of the cells, careful saline rinses of the lower halves of the cells and also uncentrifuged controls were refrigerated, and the next day were assayed for tumour-damaging and for fever-producing activity. Results are summarized in Table 4. 
In the first partition experiment (Fig. $4 \mathrm{~B}$ ) at a dilution which in the uncentrifuged control would have given seventy times the ED 50, the supernatant had no detectable tumour-damaging activity; and also had no pyrogenic activity at a dilution which would have had 1200 times the MPD. All of the tumour-damaging activity and a large amount of the fever-producing activity were recovered, however, from the lower part of the cell. The appearance of the schlieren pattern indicated that a considerable amount of the slower sedimenting component $(3 \cdot 4 S)$ was still present in the supernatant. Chemical determination was not possible because of the low level of the bacterial polysaccharide.

Table 4. Fractions of the total biological activities recovered from compartments of the partition cell

These values were determined by serial dilution and finding the approximate ED 50 values for the tumour-damaging activity and the MPD values for pyrogenicity and by comparing these to the controls.

Expt.

(Fig.)

Activity

Supernatant fluid

Subnatant fluid

Rinse

Plug removed before centrifuging
1

(4 B)

$$
\begin{gathered}
\text { Tumour } \\
<\frac{1 \dagger}{70}
\end{gathered}
$$$$
\frac{6}{7}
$$$$
\frac{1}{7}
$$

$\frac{1}{7}$

$-$

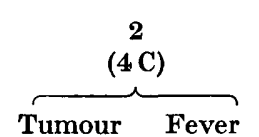

\begin{tabular}{|c|c|}
\hline \multicolumn{2}{|c|}{$\begin{array}{c}\mathbf{3}^{*} \\
(\mathbf{4} \mathbf{E})\end{array}$} \\
\hline Tumour & Fever \\
\hline 1 & 1 \\
\hline$\overline{20}$ & $\overline{20}$ \\
\hline 10 & 10 \\
\hline$\overline{20}$ & $\overline{20}$ \\
\hline$\frac{4}{9}$ & $\dagger$ \\
\hline 0.5 & \\
\hline$\overline{20}$ & \\
\hline
\end{tabular}

* Bioassays carried out 1-6 days after the ultracentrifugation.

$\dagger$ Sufficient experiments were not carried out to find the ED 50 or the MPD value, since the available concentration was insufficient.

These results indicated that the active components sedimented rapidly and that the slow sedimenting component $(3 \cdot 4 S)$ was not pyrogenic, and that it was also not tumour damaging, when the assays were carried out at the maximum available concentration.

In the second partition experiment where some of the more rapidly sedimenting material remained in the supernatant fluid (Fig. 4C), the supernatant fluid had about one-seventh of the original tumour damaging and also of the pyrogenic activity, while the residual activities were found in the lower half of the cell. On the basis of the bioassays of the supernatant fluid, sedimentation constant calculations by the method of Yphantis \& Waugh $(1956 a, b)$ gave a figure of $15 \cdot 7 \pm 0 \cdot 5 S$ for both the tumourdamaging and fever-producing activity.

In the third partition experiment (Fig. $4 \mathrm{E}$ ), in which the bacterial polysaccharidelysozyme solution was sedimented, bioassays showed that the fraction of the original tumour-damaging and pyrogenic material which remained in the top half of the cell was $1 / 20$, giving a calculated sedimentation constant of $8 \cdot 7 \pm 0 \cdot 3 S$ for both of 
these activities. In the insoluble material, which was removed before the partition cell analysis, there was only one-fortieth of the tumour-damaging potency, while the pyrogenic activity was high.

\section{DISCUSSION}

The tumour-damaging activity of the anionic bacterial polysaccharide was decreased when it was mixed in aqueous solution with typical cationic macromolecules, such as ribonuclease or polymyxin B. Furthermore, this reduction was annulled when an anionic macromolecule (polyglucose sulphate), with stronger dissociating groups and higher negative charge density than the bacterial polysaccharide, was added. These phenomena indicated direct complexing, and uncoupling, of charged macromolecules. In the first step the cationic macromolecules presumably blocked the sites, or components, in the bacterial polysaccharide responsible for its tumournecrotizing potency. In the second, the stronger anionic polyglucose sulphate formed complexes with the cationic macromolecule, and thus liberated the tumourdamaging site of the bacterial polysaccharide. This mechanism is similar to the one we proposed on the reversible inhibition of enzymes (Mora \& Young, 1959), and on the blocking of toxicity (Mora, Young \& Shear, 1959).

Lysozyme, however, did not decrease the tumour-damaging activity of the bacterial polysaccharide at first; on the contrary, the tumour-damaging activity was somewhat enhanced when lysozyme and the bacterial polysaccharide were incubated for short periods. Apparently the complexing in this instance was with different components, or sites, of the bacterial polysaccharide, from those involved in the case of the other cationic macromolecules. There was no doubt of immediate complex formation: titration and precipitation curves (Fig. 3) indicated neutralization at a weight ratio of 1.5-2 lysozyme to bacterial polysaccharide, and the lysozyme was present in about the same ratio in non-dialysable complex both in water and in saline (Table 3). Electrostatic complexing with lysozyme must have left the tumour-damaging component or site free to exert its biological action. Addition of polyglucose sulphate to the complex of lysozyme and the bacterial polysaccharide decreased the tumour-damaging effect below that of the bacterial polysaccharide control. The fever-producing component was concentrated in the insoluble interaction product, recovered by low-speed centrifugation (Table 4, expt. 3).

Lysozyme was different from other cationic macromolecules in another respect, it reduced pyrogenicity of the bacterial polysaccharide but only through a slow process, taking 1-2 weeks to show a marked effect. Pyrogenic activity of the bacterial polysaccharide at ten times the minimum pyrogenic dose was completely abolished, and a considerable reduction of fever activity occurred even at 160 times the minimum pyrogenic dose (cf. Fig. 1C). It was necessary to have a relatively high bacterial polysaccharide concentration during incubation. These two features (a slow process, and high substrate concentration increasing the rate of the process) suggest that the reduction of pyrogenic activity occurred through an enzymic process, probably through slow breakdown of certain portions of the bacterial polysaccharide. This enzymic type of activity of lysozyme was blocked by polyglucose sulphate, as expected on the basis of our previous work on lysozyme inhibition (Mora \& Young, 1959). 
The above findings suggested that different sites or species of the bacterial polysaccharides were responsible for the tumour-damaging and for the feverproducing activity.

Two approaches were used to investigate further the heterogenicity of the bacterial polysaccharide. One was partial precipitation with lysozyme and the study of distribution of the tumour-damaging activity between the supernatant and the sediment upon centrifugation; the other was partition cell analysis of both tumourdamaging and pyrogenic activities.

The precipitation and centrifugation method indicated that about $22 \%$ of the bacterial polysaccharide, which sedimented in saline solution, was devoid of, or at least, had very low, tumour-damaging activity; it also confirmed the fact that both soluble and insoluble complexes are formed with lysozyme in aqueous solution (cf. Table 2).

The results of the partition cell analysis of the bacterial polysaccharide showed that both the pyrogenic and the tumour-damaging activities were associated with components which had a high sedimentation rate $(>10 S)$, and which probably were large macromolecular complexes. The major component of the bacterial polysaccharide $(3 \cdot 4 S)$ was not pyrogenic in the maximum dose tested $(1200 \times$ MPD). This component also had lower tumour-damaging activity than the original $(<1 / 70)$. The limitations of the available quantities for tumour-damaging assay and the limited sensitivity of this assay does not allow further conclusion from this experiment.

The faster sedimenting components did not show up in ultra-centrifugation after the treatment with lysozyme (Fig. 4D). Apparently, these were the components which were preferentially precipitated, and also probably these were the ones digested eventually by the lysozyme. The supernatant fluid of the interaction product showed two slow sedimenting components (Fig. 4, D and E). One of these might be a breakdown product, the other an association complex of the slow sedimenting component with lysozyme.

The ultracentrifuge experiments did not give information on the actual size of the active components. It is possible that the sites which were responsible for pyrogenic or tumour-damaging activity were of much smaller size than the sedimentation constant indicates, and they were only incorporated rather firmly in a larger macromolecular entity which, when broken down by hydrolysis, resulted in complete loss of the biological activities.

It should be kept in mind that the enzymic type of digestion of the high molecular weight fever-producing components was not completely selective, since after 2 weeks' incubation there was also some decrease of tumour necrotic activity, to about onehalf of that of the original polysaccharide. Also, our data do not justify the assumption of completely independent physico-chemical entities, one type being purely pyrogenic, the other tumour-damaging. The separation and the different behaviour of the functions was demonstrated, of course, only to the limits of the sensitivity of our biological assays.

The above reported experiments, however, indicated: that two of the biological activities (the pyrogenic and the tumour-damaging activity) of the bacterial polysaccharide complex from Serratia marcescens probably are caused by different physico-chemical entities; and that they behave differently in macromolecular 
interaction and separation of them is a possibility in an active form when macromolecular size is retained. However fractionation on a preparative scale should be carried out to prove this last point.

The original observations on pyrogenicity were carried out at the suggestion of, and in collaboration with, Dr F. Rosen. Dr W. Carroll and Dr H. Kahler helped with the ultracentrifuge experiments. Mr Ellis Sheets provided experimental assistance. We would like to thank Dr M. J. Shear for his interest throughout this work.

\section{REFERENCES}

Burrows, W. (1951). Endotoxins. Annu. Rev. Microbiol. 5, 131.

Creech, M. J., Koehler, L. H., Havas, H. F., Peck, R. M. \& Andre, J. (1954). Preparation and chemical properties of polysaccharide-lipid complexes obtained from Serratia marcescens and Escherichia coli. Cancer Res. 14, 817.

Fisher, H. (1959). Biochemical Aspects of Natural Resistance torvard Infection. In A Symposium on Molecular Biology, ed. by R. E. Zirkle, p. 214. Chicago: University Press.

Fromme, I., Lüderitz, O., Nowotryy, A. \& Westphal, O. (1958). Chemische Analyse des Lipopolysaccharides aus Salmonella abortus equi. Pharm. Acta helvet. 33, 391.

Irawa, M., Koepfit, J. B., Mudd, S. G. \& Niemann, C. (1952). An agent from E. coli causing haemorrhage and regression of an experimental mouse tumor. I. Isolation and properties. J. nat. Cancer Inst. 13, 157.

Ikawa, M., Koepfi, J. B., Mudd, S. G. \& Niemann, C. (1954). An agent from $E$. coli causing haemorrhage and regression of an experimental mouse tumor. V. Behaviour of the agent in the presence of various reagents. J. nat. Cancer Inst. 14, 1195.

LANDY, M. \& ShEar, M. J. (1957). Similarity of host responses elicited by polysaccharides of animal and plant origin and by bacterial endotoxins. J. exp. Med. 106, 77 .

Malmgren, H. (1954). Physicochemical characteristics of the tumor-necrotizing agent from Serratia marcescens. (Shear's polysaccharide.) J. nat. Cancer Inst. 14, 1119.

Mora, P. T. \& Young, B. G. (1958). Interaction between synthetic polyglucose sulphate and biologically active basic polypeptides and proteins. Nature, Lond. 181, 1402.

Mora, P. T. \& Young, B. G. (1959). Reversible inhibition of enzymes by interaction with synthetic polysaccharide macroanions. Arch. Biochem. Biophys. 82, 6.

Mora, P. T., Young, B. G. \& Shear, M. J. (1959). Reduction of toxicity of cationic macromolecules by complexing with anionic derivatives of synthetic polyglucoses. Nature, Lond. 184, 431.

Neter, E. Gorzynski, E. A., Westphal, O., Luderitz, O. \& Kuumpp, D. J. (1958). The effects of protamine and histone on enterobacterial lipopolysaccharides and hemolysis. Canad. J. Microbiol. 4, 371.

Rathgeb, P. \& Sylvén, B. (1954a). Fractionation studies on the tumor necrotizing agent from Serratia marcescens (Shear's polysaccharide). J. nat. Cancer Inst. 14, 1099.

Rathgeb, P. \& Sylvén, B. (1954.b). Chemical studies on the tumor necrotizing agent from Serratia marcescens (Shear's polysaccharide). J. nat. Cancer Inst. 14, 1109.

Ribi, E., Hoyer, B. H., Milner, K. C., Perrine, T. D., Larson, C. L. \& Goode, G. (1960). Physical and chemical analysis of endotoxin from Salmonella enteritidis. J. Immunol. 84, 32.

Shear, M. J. \& Turner, F. C. (1943). Chemical treatment of tumours. V. Isolation of the hemorrhage-producing fraction from Serratia marcescens (Bacillus prodigiosus) culture filtrate. J. nat. Cancer Inst. 4, 81.

Shear, M. J., Perrault, A. \& Adams, J. R., Jun. (1943). Chemical treatment of tumors. VI. Method employed in determining the potency of hemorrhage-producing bacterial preparations. J. nat. Cancer Inst. 4, 99.

Skarnes, R. C. \& Watson, D. W. (1955). The inhibition of lysozyme by acidic polymers from pathogenic bacteria. J. Bact. 70, 110. 
Thомas, L. (1954). The physiological disturbances produced by endotoxins. Annu. Rev. Physiol. 16, 467.

Westphat, O., Nowotny, A., Lüderitz, O., Hurni, H., Eichenberger, E. \& SchönHolzer, G. (1958). Die Bedeutung der Lipoid-Komponente (Lipoid A) für die biologischen Wirkungen bakterieller Endotoxine (Lipopolysaccharide). Pharm. Acta helvet. 33, 401.

Wood, J. W. \& Mora, P. T. (1958). Synthetic polysaccharides. III. Polyglucose sulfates. J. Amer. Chem. Soc. 80, 3700.

Yphantis, D. W. \& WAUGH, D. C. (1956a). Ultracentrifuge characterization by direct measurement of activity. I. Theoretical. J. phys. Chem. 60, 623.

Yphantis, D. W. \& WAUGH, D. F. (1956b). Ultracentrifuge characterization by direct measurement of activity. II. Experimental. J. phys. Chem. 60, 630. 